\title{
A RAIZ DO PENSAMENTO COLONIAL NA INTOLERÂNCIA RELIGIOSA CONTRA RELIGIÕES DE MATRIZ AFRICANA ${ }^{1}$
}

\author{
Nathalia Vince Esgalha Fernandes ${ }^{2}$
}

Resumo: O presente artigo tem por objetivo explicitar as manifestações de discriminação e intolerância religiosas contra os praticantes como atos que podem ser caracterizados como racismo religioso, compreendendo a sua formação a partir do pensamento colonial. $\mathrm{O}$ artigo traz um breve panorama, da prática discriminatória e criminalização histórica contra essas religiões no Brasil, apresenta uma discussão das categorias: intolerância religiosa, discriminação e racismo e, a partir dos aportes do pensamento colonial, debate a relação entre o racismo presente na formação latino-americana e o fenômeno da discriminação contra as religiões afro-brasileiras na atualidade.

Palavras-chave: religiões de matriz africana; racismo; discriminação; intolerância religiosa; colonialidade.

\section{Introdução}

A intolerância religiosa se tornou uma das principais causas de perseguição das minorias no mundo e com frequência as atitudes de intolerância não vêm isoladas; componentes de etnocentrismo, racismo, questões econômicas e de manutenção do status quo são algumas das motivações que podem acompanhar tal manifestação.

Constitucionalmente o Brasil tem positivado desde a Constituição de 1891 o status de Estado não confessional, isso significa que o Estado não possui uma religião oficial e respeita a todas as religiões. Na mais recente Constituição Federal, de 1988, a liberdade

\footnotetext{
${ }^{1}$ O presente trabalho foi realizado com apoio da CAPES - Coordenação de Aperfeiçoamento de Pessoal de Nível Superior. O texto versa sobre questões publicadas em sua dissertação de mestrado e em pesquisa pela autora para sua Tese de Doutorado, orientada pela professora doutora Rebecca Lemos Igreja.

${ }^{2}$ Doutoranda em Ciências Sociais pelo Departamento de Estudos Latino Americanos (ELA) - Universidade de Brasília. Integrante do Calundu - Grupo de Estudos sobre Religiões Afro-Brasileiras. nathaliavef@gmail.com.
} 
de crença e o exercício de culto são garantidos em seu artigo $5^{\circ}$, inciso $\mathrm{VI}^{3}$, também presente no Estatuto da Igualdade Racial, Lei 12.288/2010. No entanto, o direito ao respeito religioso não é praticado pela sociedade, o cristianismo desde a conquista segue atuando como religião pública e está imbricado na estrutura do Estado, tampouco é assegurada a liberdade de culto de maneira satisfatória pelas instituições: são muitos os casos cotidianos de intolerância religiosa, discriminação e racismo contra seguidores das religiões afro-brasileiras no Brasil, como é o exemplo de um caso recente, em 2015, da menina Kayllane de 11 anos, que foi atingida por pedradas na cabeça ao sair de uma cerimônia de candomblé no Rio de Janeiro (UOL, 2015, on-line).

É histórica a luta das religiões afro-brasileiras contra a intolerância. O desrespeito, demonização de suas divindades cultuadas, agressões físicas, verbais e atentados ao espaço físico dos templos são apenas algumas das atitudes de intolerância, discriminação que os praticantes sofrem. Os preconceitos e ações direcionados contra esse grupo, o de praticantes das religiões afro, em todos os países americanos em que essas religiões são praticadas, têm a ver com a formação da estrutura estatal sob a colonial modernidade, visto que, para o colonizador, evangelizar as populações submetidas (indígenas e africanos escravizados) era parte fundamental da empreitada colonial.

Tendo em vista este cenário, o artigo pretende abordar o debate da discriminação a religiões de matriz africana ${ }^{4}$. O objetivo do trabalho é explicitar as manifestações de discriminação e intolerância religiosas contra os praticantes como atos que podem ser caracterizados como racismo religioso, compreendendo a sua formação a partir do pensamento colonial.

O artigo será dividido em três partes. A primeira parte do artigo trará um breve panorama da criminalização histórica e prática discriminatória contra essas religiões no Brasil, a segunda parte pretende explicitar as categorias: intolerância religiosa, discriminação e racismo, e a terceira apresenta o pensamento colonial nos reflexos desse pensamento, explicando a relação entre o racismo presente na formação latino-americana e o fenômeno da discriminação contra as religiões afro-brasileiras nos dias de hoje, religiões que deveriam ser entendidas majoritariamente como um bem cultural imaterial

\footnotetext{
${ }^{3}$ A intolerância contra religiões afro-brasileiras à luz da constituição brasileira de 1988 e da declaração universal dos direitos humanos de 1948.

4 "Religiões de matriz africana é um termo geralmente utilizado para designar as práticas religiosas desenvolvidas pelos negros no Brasil” (ROCHA, 2011.p.1).
} 
Revista Calundu - vol. 1, n.1, jan-jun 2017

a ser respeitado e preservado, pela sua história de resistência dentro da sociedade brasileira.

\section{Criminalização e discriminação a religiões de matriz africana no Brasil}

As repressões às religiões de matriz africana iniciam-se ainda em período escravocrata, o país era desde o início da colonização dominado pela Igreja Católica, de forma que qualquer outra manifestação religiosa era entendida como contravenção penal. Neste momento, os africanos escravizados eram objetos de posse e seres indignos de humanidade, tampouco poderiam ter crença. No período colonial, o escravo trazido para o Brasil era batizado já no porto onde partia da África ou quando chegava ao novo continente, sendo marcado à brasa ou sendo colocada uma argola de ferro em seu pescoço para identificar o seu novo status de cristão (SILVEIRA, 2006).

Dessa forma, os escravizados eram misturados e submetidos à nova religião. Em muitos momentos, os senhores permitiam aos escravos realizarem as suas festas e batuques em épocas de melhor tratamento dos escravos, motivados pelo arrocho do tráfico negreiro e pelo encarecimento desta mão de obra com objetivo de mantê-los vivos por mais tempo (SILVEIRA, 2006, p.159). Tais festas e danças, ainda que mal vistas, não eram proibidas pelo código canônico. Renato da Silveira explica que, além disso, desde Roma, a Igreja Católica usava como estratégia expansionista o sincretismo com cultos pagãos. A ideia era permitir a prática religiosa não cristã, desde que os demais grupos assumissem e apresentassem o catolicismo como religião superior e sua crença como uma manifestação do mesmo.

Na sociedade colonial do século XVIII, as práticas religiosas africanas ${ }^{5}$ eram consideradas manifestações de magia ou feitiçaria, e passíveis de punição pelo código canônico e perseguidas pela igreja e pelas autoridades. Yvonne Maggie descreve que "a crença na magia e na capacidade de produzir malefícios por meios ocultos e sobrenaturais é bastante generalizada no Brasil desde os tempos coloniais" (1992, p.22). Assim, a religiosidade negra teve efeitos marcantes no imaginário dos agentes colonizadores sob um misto de admiração e de terror encarnado nas figuras das 'feiticeiras' e 'curandeiras'

\footnotetext{
${ }^{5}$ Calundu até meados do século XVIII era o nome dado para os cultos afro-coloniais (SILVEIRA, 2006, p.
} 177). 
Revista Calundu - vol. 1, n.1, jan-jun 2017

(BASTIDE apud FERREIRA, 1985, p. 96); estas religiosidades eram chamadas 'curandeirismo', 'feitiçaria', 'espiritismo' e ‘baixo espiritismo' até a metade do séc. XX.

A partir da República, o Estado brasileiro cria mecanismos reguladores do combate aos "feiticeiros", introduzindo as práticas das religiões afro-brasileiras no Código Penal de 1890 em três artigos: 156, 157, 158 , que versam sobre a prática ilegal da medicina, prática de magia e proibição ao curandeirismo (MAGGIE, 1992, p. 43).

No século XX, são organizadas formas de controle institucional a essas práticas, organizam-se as Delegacias de Jogos e Costumes que passam a exigir registro, alvará e licença para a existência legal dos centros. Em 1941, dando continuidade à criminalização, o chefe de polícia passa a exigir, além do registro na delegacia distrital e na especializada, registros na Delegacia Especial de Segurança Pública e na Delegacia Geral de Informações, para obter os antecedentes políticos, sociais e criminais de seus componentes (op. cit., p. 46). Em 1942, é aprovado um novo Código Penal, os artigos que tratam do assunto são: 282, 283, 284 - crimes contra a saúde pública, charlatanismo e curandeirismo. Na evolução legislativa, a diferença é que os artigos não vão proibir ou punir todo espírita, curandeiro ou praticante de magia e sim apenas os que praticam o mal.

\footnotetext{
${ }^{6}$ Código Penal de 1890:

“Art. 156. Exercer a medicina em qualquer de seus ramos, a arte dentária ou a farmácia; praticar a homeopatia, a dosimetria, o hipnotismo ou magnetismo animal, sem estar habilitado segundo as leis e regulamentos.

Penas - de prisão celular por um a seis meses, e multa de $100 \$ 000$ a $500 \$ 000$.

Parágrafo único. Pelos abusos cometidos no exercício ilegal da medicina em geral, os seus atores sofrerão, além das penas estabelecidas, as que forem impostas aos crimes que derem casos."

Art. 157. Praticar o espiritismo, a magia e seus sortilégios, usar de talismãs e cartomancias, para despertar sentimentos de ódio ou amor, inculcar cura de moléstias curáveis ou incuráveis, enfim, para fascinar e subjugar a credulidade pública:

Penas - de prisão celular de um a seis meses, e multa de $100 \$ 000$ a $500 \$ 000$.

Parágrafo 1. ${ }^{\circ}$ Se, por influência, ou por consequência de qualquer destes meios, resultar ao paciente privação ou alteração, temporária ou permanente, das faculdades psíquicas.

Penas - de prisão celular por um ano a seis anos, e multa de $200 \$ 000$ a $500 \$ 000$.

Parágrafo $2^{\circ}$ Em igual pena, e mais na privação de exercício da profissão por tempo igual ao da condenação, incorrerá o médico que diretamente praticar qualquer dos atos acima referidos, ou assumir a responsabilidades deles. (...).".

"Art. 158. Ministrar ou simplesmente prescrever, como meio curativo, para uso interno ou externo, e sob qualquer forma preparada, substância de qualquer dos reinos da natureza, fazendo ou exercendo assim, o ofício do denominado curandeirismo.

Penas - de prisão celular por um a seis meses, e multa de $100 \$ 000$ a $500 \$ 000$.

Parágrafo único. Se do emprego de qualquer substância resultar a pessoa privação ou alteração, temporária ou permanente, de suas faculdades psíquicas ou funções fisiológicas, deformidades, ou inabilitação do exercício de órgão ou aparelho orgânico, ou, em suma, alguma enfermidade:

Penas - de prisão celular por um a seis anos, e multa de $200 \$ 00$ a $500 \$ 000$.

Se resultar morte:

Pena - de prisão celular por seis a vinte e quatro anos."
} 
Neste ponto da história, começa haver uma diferenciação das práticas mediúnicas e o legislador começa a aceitar alguns tipos de espiritismo, os de matriz africana, contudo, continuavam criminalizados e associados ao mal, como podemos observar a partir da constatação da pesquisa de Yvonne Maggie ${ }^{7}$ em processos criminais no século XX: "No caso aqui estudado há os que conseguem fazer ouvir melhor suas acusações. Aparentemente, os negros pobres são, de um modo geral, os condenados. Os espíritas das federações, por outro lado, conseguem, aos poucos, se defender das acusações" (op. cit., p. 120-1). Em outro trecho dos processos, fica claro que é a ligação com os costumes africanos o mais condenável da prática criminalizada: "Dizendo-se do rito africano, os acusados talvez queiram dizer que eram puros, alegar a sua pertença à legítima tradição dos orixás (...) no Rio, os sinais da africanidade eram justamente aqueles que deslegitimavam" (op. cit., p. 128). Em mais um achado de pesquisa, a acadêmica relata que os peritos começam a estabelecer distinções hierarquizadas dos rituais, adjetivandoos como alto e baixo espiritismo, magia branca e negra, etc. (op. cit., p. 158).

Esses achados demonstram a associação clara dos cultos africanos ao mal, da figura da religião negra ao menos evoluído, ao engano e ao charlatanismo. Também se pode observar o aspecto moral e discriminatório na criminalização das práticas religiosas negras, tanto no início do século XIX como no século XX, onde há diferença na comparação entre o tratamento e condenação dos ritos africanos e do espiritismo "branco".

A obrigatoriedade de registro nas Delegacias de Jogos e Costumes é revogada somente em 1976. As perseguições continuaram no período da ditadura militar e arrefeceram com a Constituição Federal de 1988, ainda que casos de conflito destas religiões com a segurança pública ainda sejam notificados.

Nos dias de hoje, o conflito se apresenta mais destacadamente em casos de discriminação e intolerância religiosa. Reportagens na mídia regular apontam para diversos casos de intolerância religiosa nos últimos anos, apresentando um crescimento das ocorrências.

Em uma pesquisa da Secretaria de Direitos Humanos da Presidência da República (SDH) de 2011 a 2015, sobre o tema da intolerância religiosa contra as mais diversas

\footnotetext{
${ }^{7}$ É importante ressaltar que a autora Yvonne Maggie em seu trabalho não faz a relação entre esses achados de pesquisa e manifestações de racismo, como é o ponto colocado neste artigo. A posição aqui defendida diverge da autora em muitos de seus trabalhos, a opção por utilizar a autora deve-se à qualidade da etnografia realizada no assunto, tornando o trabalho imprescindível para o artigo aqui proposto.
} 
religiões, foram encontradas 94 reportagens sobre violência física tendo como motivo a crença religiosa da vítima, incluindo homicídios; 98 notícias sobre casos que relatem ataque com retenção, subtração, destruição parcial ou total de objetos religiosos, de espaços físicos que abriguem templos religiosos e casas e pessoas, em função de sua crença religiosa, além da invasão dos mesmos (os casos mais comuns encontrados com esse tema são os que relatam terreiros incendiados, destruição de estátuas e imagens); e 92 notícias de casos de violência e intolerâncias cotidianas, que ocorrem em situações comuns do dia a dia (são esses casos onde atividades do cotidiano são impedidas ou prejudicadas por questões religiosas). Na mídia, notícias que trazem o assunto de violências e intolerâncias religiosas ligadas ao racismo foram 13. Em uma de suas conclusões, a pesquisa aponta que os fiéis das religiões de matriz africana são os que mais sofrem discriminação religiosa. (SDH-PR, 2016).

Segundo os dados do Disque Direitos Humanos, o Disque 100, da SDH, período de 2011 a 2014, calcula-se que das denúncias identificadas com a religião atacada, 35\% são denúncias de discriminação contra religiões de matriz africana (EBC, 2015, on-line). Ainda sobre esses dados, a população negra é mais vitimada. Entre as 345 vítimas que declararam a cor, 210 são pretas ou pardas. O número representa $35,2 \%$ do total de vítimas e 60,8\% do total de vítimas que declararam a cor de pele (EBC, 2015, on-line).

Os gestores do Disque 100 explicam e associam a cifra ao racismo e à história da sociedade brasileira de negação dessa tradição religiosa (EBC, 2015, on-line). O crescimento das religiões neopentecostais em todo país e o antagonismo que estas religiões promovem com as religiões de matriz africana (DIAS, 2012 p.68) também poderia explicar o crescimento das ocorrências, ainda que esta análise tivesse que ser feita de forma cuidadosa.

Outro dado expõe que, em 2015, as denúncias de discriminação religiosa computaram um aumento de 69,13\% em relação ao ano anterior. Candomblecistas e umbandistas são os mais recorrentes alvos dos ataques também segundo o Disque 100 (BDF, 2017, on-line). Os dados computam apenas os casos denunciados e, pelo perfil dos praticantes da religião, incluídos nas camadas mais baixas da população, e por seu histórico com a institucionalidade, pode-se presumir que o número de ocorrências diárias seja muito maior. Quando denunciados, a maior parte dos casos não são punidos.

Somando o histórico brasileiro de criminalização e demonização das práticas afrorreligiosas com os episódios recentes de discriminação classificados como intolerância religiosa, pode-se concluir que os praticantes dessas religiões são um grupo 
Revista Calundu - vol. 1, n.1, jan-jun 2017

em situação de vulnerabilidade que deve receber atenção do Estado no que concerne à garantia da liberdade religiosa prevista na constituição e ao combate à discriminação.

\section{Intolerância religiosa, discriminação ou racismo religioso?}

Proteger e garantir direitos a uma população vulnerabilizada envolve muitas questões, existem uma série de lutas e embates que podem ser observadas por dentro do Estado, e todas as fontes de atuação, e de fundamentação teórica, influenciam nesse processo. A discussão conceitual e disputas do mesmo na sociedade refletem na efetividade dos mecanismos de proteção do sujeito em situação de discriminação, além do que o envolvimento ou descolamento do conjunto social na materialização (em forma de política de Estado) de um direito é fundamental para o sucesso desse processo (FLORES, 2005, p.18).

Isso significa que a discussão de como caracterizar as ações e manifestações contra os praticantes de religiões afro-brasileiras é fundamental para compreender o fenômeno e encontrar formas para avançar na solução do problema; além disso, nos meios ativistas já existem manifestações de descontentamento com o conceito de "intolerância religiosa" tornando a discussão ainda mais relevante.

\section{Intolerância Religiosa}

A discriminação e intolerância religiosa, como vimos, são fenômenos frequentes e estatisticamente superiores a outras religiões no caso dos praticantes de religiões de matriz africana. Recentemente, abriu-se o debate sobre como se deve nomear essa discriminação contra essas religiões, pois o termo "intolerância religiosa" nos meios ativistas tem parecido insuficiente para expressar o fato. Os praticantes reivindicam respeito e chamam atenção para as manifestações de racismo constantes, afirmam que o melhor termo para definir estas ações seria "racismo religioso", argumentando que outras religiões não cristãs não sofrem o mesmo tipo de preconceito e argumentam que esse preconceito estaria ligado à formação colonial, à divisão e valoração racial negativa, influenciando na compreensão da religião. Em uma reportagem de jornal, selecionamos a seguinte fala emblemática: 
Revista Calundu - vol. 1, n.1, jan-jun 2017

Não quero tolerância, eu quero respeito. Tolerar é uma forma de dizer que a minha religião está errada, mas dá para fingir que não. Preciso é que respeitem o candomblé da mesma maneira que eu respeito todas as religiões. Já vieram na porta da minha tenda espiritual e disseram que o diabo estava aqui. Bom, eu sempre respondo duramente a esse tipo de coisa e falei que realmente o diabo estava lá porque a própria pessoa tinha trazido (FOLHAPE, 2016, on-line).

A partir desta fala, podemos observar que o interlocutor em sua experiência compreende a tolerância a partir de uma denotação mais literal, significando indulgência, condescendência, conforme o seu sentido semântico. Para Wagner Sanz (2012, p. 249), o conceito de tolerância está ligado a uma perspectiva multicultural de convivência e inclusão entre raças, etnias e culturas diferentes, onde tolerância, “(...) significa convivência com comportamentos, ideias e discursos diferentes e requer, pelo menos, que alguns princípios de convivência sejam respeitados". Sendo assim, a não prática da tolerância, seu antônimo, seria a intolerância.

O relatório da Secretaria de Direitos Humanos ao definir intolerância religiosa diz:

Será considerado como intolerância e violência religiosa o conjunto de ideologias e atitudes ofensivas a diferentes crenças e religiões, podendo em casos extremos tornar-se uma perseguição. Entende-se intolerância religiosa como crime de ódio que fere a liberdade e a dignidade humana, a violência e a perseguição por motivo religioso são práticas de extrema gravidade e costumam ser caracterizadas pela ofensa, discriminação e até mesmo por atos que atentam à vida (SDH-PR, 2016).

Intolerância se refere a uma atitude de inflexibilidade e intransigência com relação a algo, falta de tolerância, de condescendência. O teórico Enrique Dussel ao se debruçar sobre a categoria propõe:

Denominaremos como intolerante a la posición intransigente ante posibles oponentes. Por ello la intolerancia es dogmática, indicando así la unidad entre una cierta teoría de la verdad y el poder político. El intolerante afirma "poseer" la verdad o encontrarse en un acceso privilegiado con respecto a lo que se conoce como "verdadero" (2004, p.1).

A intolerância religiosa pode ser compreendida como uma prática definida pelo não reconhecimento da veracidade de outras religiões. Relaciona-se então com a incapacidade dos indivíduos em compreender crenças diferentes da sua e nos casos concretos de manifestações de intolerância no campo prático, segundo Silva Jr: 
(...) a intolerância religiosa é uma expressão atitudes fundadas nos preconceitos caracterizadas pela diferença de credos religiosos praticados por terceiros, podendo resultar em atos de discriminação violentos dirigidos a indivíduos específicos ou em atos de perseguição religiosa, cujo alvo é a coletividade (2009, p.128).

O professor Tomás y Valiente rejeita a tolerância e a define como uma “concesión graciosa y unilateral que el dominante hace al dominado, trata de una actitud que podría expresarse en la frase - te tolero, pero podría no hacerlo” (apud MALGESINI, 2000, p. 393-394). As atitudes de intolerância, como a perspectiva de Enrique Dussel nos explica, estão conectadas com a teoria da verdade e o poder político, a relação dominante e dominado aqui se faz presente, pois uma atitude de "tolerância" só se pode promover ao sujeito com menos poder, o sujeito dominante/hegemônico não necessita da indulgência ou condescendência de sujeitos subordinados hierarquicamente a ele.

\section{Discriminação ${ }^{8}$}

Discriminação, em uma análise etimológica, significa distinção ou separação (dis $=$ dividir e cerno $=$ distinguir), a palavra "responde a uma forma de trato diferenciado sobre indivíduos ou grupos" (MALGESINI, 2000, p.119), portanto o termo em si não é negativo. $\mathrm{O}$ que torna a discriminação uma prática problemática são as consequências negativas reais ou possíveis do ato discriminatório para o indivíduo ou grupo discriminado. Cabe aqui salientar que não se fala em trato desfavorável e sim de diferença, apesar de esse trato de maneira diferente poder ser muitas vezes caracterizado como injusto. É importante ressaltar também a diferença entre diferença e desigualdade: "toda desigualdade supõe diferença, mas nem toda diferença têm que expressar uma relação de desigualdade" (op. cit., p.120).

Dessa forma, o conceito de discriminação se refere essencialmente à questão do trato desigual, compreende-se que a discriminação existe quando uma parte da população recebe trato desigual com relação ao conjunto (BIROU apud MALGESINI, 2000, p.119).

Outro ponto importante é que a noção de discriminação social tem um componente coletivo ou social, não pode ser considerada, nessa perspectiva, a partir do trato individual, pois a relação, ou a característica que o indivíduo carrega, e que é o objeto da

\footnotetext{
${ }^{8}$ Essas reflexões sobre discriminação e sobre colonialidade também podem ser encontradas em minha dissertação de mestrado: Fernandes, 2016. Vide bibliografia.
} 
discriminação, é sempre concernente a um determinado grupo social, ou seja, o fundamento para o trato discriminatório diz respeito a distintas marcas do sujeito e/ou do grupo a que pertence, como sexo ou orientação sexual, religião, nacionalidade, etnia/raça, deficiência ou pertença a um sindicato (FASSIN, 2008, p. 50-51). Dessa forma, as causas da discriminação de grupos considerados em situação de vulnerabilidade, muitas vezes, são justamente as características que lhes dão identidade (ANCIRA, 2007), ou seja, no caso da discriminação religiosa, é o fato do indivíduo professar determinado credo religioso que o torna vulnerável.

Assim, o fenômeno discriminatório é composto de fatores culturais que se alimentam de preconceitos, que determinam as pautas de conduta dos indivíduos e a forma de relacionar-se com certas pessoas e coletivos sociais (ANCIRA, 2007). Há deste modo uma relação estreita entre a discriminação e o preconceito, a distinção entre eles é o comportamento das ações, assinalando-se o comportamento na esfera do preconceito e as ações como a discriminação em si. Distinguem-se atitudes, propósitos e disposições interiores de comportamentos de ações concretas (GUIMARÃES, 1998, p.14). O preconceito é por diversas vezes a motivação para ações discriminatórias.

O estereótipo já é uma imagem ligada ao campo conceitual ou cognitivo, que supõe uma valoração (ALLPORT apud MALGESINI, 2000, p.330). Segundo Castellanos Guerrero (1998, p.24): “O estereótipo precede ou fundamenta o preconceito. Estereótipos e estigmas são considerados como novas formas de dominação, heranças que perduraram no imaginário social e que expressam situações cotidianas de conflito".

Outro conceito importante para nos debruçarmos, nesse contexto, é o etnocentrismo. Algumas vezes considerado uma forma de preconceito, é caracterizado pelo tratamento do próprio grupo como medida dos demais grupos e por hierarquizar os outros como inferiores. No entanto, preconceito e etnocentrismo situam-se em campos conceituais diferentes, sendo a especificidade do etnocentrismo a valoração do outro pelas coordenadas de seu próprio grupo, mas não necessariamente uma valoração negativa. $\mathrm{O}$ etnocentrismo também é encontrado em todas as culturas e não somente na cultura ocidental, e a sua aparição como conceito é mais antiga que a do preconceito.

Historicamente, contudo, o etnocentrismo raramente aparece isolado, está sempre ligado a atitudes como o autoritarismo, o conservadorismo, o dogmatismo e o antidemocratismo (MALGESINI, 2000, p.169). Especialmente na América Latina, esse conceito traz as marcas de um passado colonial profundamente etnocêntrico, onde o etnocentrismo torna-se eurocentrismo, e isso faz com que esse conceito seja central no 
Revista Calundu - vol. 1, n.1, jan-jun 2017

debate que estamos travando sobre intolerância, discriminação e racismo religioso, conforme veremos na seção adiante.

\section{Racismo}

O racismo é um fenômeno complexo e dinâmico, que se reinventa perpassando o processo histórico, político, contextualizado, territorializado, que tanto se conforma pelas identidades políticas quanto as conforma a partir da relação dialética entre sujeitos/as e sistemas de opressão institucionalmente, nacionalmente (SEGATO, 1998), e que ainda tem o papel de auxiliar na hierarquização das relações sociais e de manter o status quo das elites nacionais.

No caso do racismo, as diferenças base para a hierarquia se manifestam na ideia de raça, onde raça seria uma característica natural da espécie Homo sapiens, encontrada pela distribuição de marcadores genéticos ou outras características fenotípicas (LEE, 2005 , p. 234). A categoria raça foi desmontada a partir do século XX, passando a ser compreendida como uma construção social (WADE, 2000, p.21).

O teórico Pierre-André Taguieff (1998) traz duas definições de racismo, que podem nos ajudar na reflexão. Para o autor, o racismo se define como a “(...) biologización de lo diferente o de las diferencias con el fin de naturalizar una inferioridad atribuida o de permitirse establecer una clasificación jerarquizante de grupos humanos”. E na segunda definição: “(...) el racismo como el conjunto de actitudes y de conductas que expresan un "horror de las diferencias", un irresistible y fundamental "rechazo del otro", una postura o una disposición heterofóbica" (op. cit., p. 4). As definições de racismo de Taguieff aproximam-se das ações das outras categorias explicitadas no texto: intolerância, etnocentrismo e discriminação, o horror às diferenças (para usar a expressão de Taguieff), a desvalorização do outro e a hierarquização dos grupos a partir de si como característica.

Assim, guardadas as diferenças conceituais, a disposição heterofóbica, seja com comportamentos ou ações, é comum. A particularidade do racismo neste caso é a característica grupal baseada na "raça", no caso a raça negra, pela qual a discriminação acontece. 
Revista Calundu - vol. 1, n.1, jan-jun 2017

\section{Colonialidade - a discriminação como ethos do continente americano.}

Como já explicitado, a negação do outro se apresenta como a raiz histórica da discriminação na América Latina, e algumas dinâmicas políticas atuais do capitalismo global ainda remetem a práticas e discursos tipicamente coloniais, uma colonialidade do poder que tem implicações nas formas contemporâneas de dominação social e na sua história político-econômica. O projeto da forte tendência de homogeneização da população como forma de integração social, orquestrado pela elite dominante do país e pela religiosidade, foi um ponto importante nesta empreitada, de forma que os desafios com relação à sobrevivência de culturas não hegemônicas e contra a discriminação são grandes.

A coexistência de distintas culturas, com uma formação política imposta e a desigualdade em termos econômicos foram características da sociedade colonial. A colonização foi um processo de submetimento e exploração brutal da população aí existente e de populações trazidas para serem escravizadas. O contato com a população do "Novo Mundo" satisfez o papel de "outro" necessário como contraponto para o estabelecimento das fronteiras do que é ser europeu e levou o colonizador europeu a ter que formular a sua visão de si e do mundo e, a partir daí, a justificar a dominação de outros povos e a exploração de suas riquezas. E isso foi feito, principalmente, a partir da criação e naturalização de diferenças entre os seres humanos que chegavam e os que ali estavam (FERNANDES, 2016, p.34).

Verificou-se que um padrão de poder foi configurado nos primeiros séculos de dominação e este determinou as relações de poder na América (QUIJANO, 2005 apud FERNANDES, 2016). Pablo Gonzáles Casanova explica que a colônia foi o fruto do contato de duas civilizações, classificadas uma (a europeia) como avançada e outra (a colonial) como mais atrasada, o que caracteriza as relações típicas do europeu evoluído e do indígena arcaico, e as formas pelas quais um domina e explora o outro, reforçando suas relações desiguais com processos discriminatórios (CASANOVA, 2002 apud FERNANDES, 2016).

A diferenciação étnico-racial na América, então, foi uma maneira de outorgar legitimidade às relações de dominação impostas pela conquista, uma nova maneira de legitimar as já antigas ideias e práticas de relações de superioridade/inferioridade entre dominantes e dominados (QUIJANO, 2005 apud FERNANDES, 2016). 
Revista Calundu - vol. 1, n.1, jan-jun 2017

Segundo Aníbal Quijano (2005, apud FERNANDES, 2016, p. 36), a formação de relações sociais fundadas na ideia de raça surge com uma referência às diferenças fenotípicas entre conquistadores e conquistados, posteriormente desenvolvida em supostas diferenças biológicas ${ }^{9}$, que na América teriam produzido novas identidades sociais (índios, negros e mestiços) e redefinido outras. Essas identidades foram associadas às hierarquias, lugares e papéis sociais correspondentes.

Para a divisão racial do trabalho que Quijano discute, cada forma de controle do trabalho esteve articulada com uma raça particular: os índios com o extermínio e a servidão; os negros com a escravidão; e por fim, os espanhóis e portugueses com o trabalho assalariado. Ou seja, residiria na adscrição de todas as formas de trabalho não remunerado às raças colonizadas, originalmente índios, negros e, de modo mais complexo, os mestiços, na América, e mais tarde, às demais raças colonizadas no resto do mundo, oliváceos e amarelos. E, segundo, na adscrição do trabalho pago, assalariado, à raça colonizadora, os brancos.

Nesse contexto, com a estrutura colonial surge o mito do eurocentrismo ${ }^{10}$. $\mathrm{O}$ eurocentrismo, como qualifica Enrique Dussel (2000, p.29) é uma manifestação de etnocentrismo. $\mathrm{O}$ etnocentrismo, como exposto, não é uma pratica exclusiva europeia, a ideologia eurocêntrica é a primeira que se pretende universal, e é a partir do descobrimento que a Europa posiciona-se como o "centro do mundo" e o reordena partir de si.

O eurocentrismo é uma teoria desenvolvimentista. A partir dele se criou no pensamento europeu uma escala evolutiva do desenvolvimento das civilizações tendo as europeias como o cume. Nesta dinâmica dos povos colonizados, a hegemonia cultural coloca o colonizador na condição de "único povo". Dessa forma, nas sociedades latinoamericanas, a unidade da nação foi construída com base na negação da diferença, criando um permanente estado de negação e conflito com os estados nacionais.

Nessa lógica, o mito que funda a versão eurocêntrica ${ }^{11}$ da modernidade é a ideia do estado de natureza como um ponto de partida do curso civilizatório cuja culminação é

${ }^{9} \mathrm{O}$ racismo científico é uma teoria iniciada no séc. XVII, onde começa a ganhar terreno a ideia de origens diferentes para os seres humanos e a hierarquização evolucionista. São concebidas diferenças biológicas para explicar as diferenças sociais e psicológicas entre os indivíduos e as sociedades. A teoria ganha força no século XIX e início do século XX.

${ }^{10}$ Quijano (2004) liga o conceito de eurocentrismo ao do etnocentrismo, apontando características étnicoraciais nas manifestações do eurocentrismo.

${ }^{11}$ É uma atitude na qual a visão ou avaliação de um grupo sempre seria baseada nos valores adotados pelo seu grupo, como referência, como padrão de valor. Trata-se de uma atitude discriminatória e preconceituosa de um grupo étnico considerando-se como superior a outro. (MALGESINI, 2000). 
a civilização europeia ou ocidental. Desse mito se origina a perspectiva eurocêntrica evolucionista, de movimento e de mudança unilinear e unidirecional da história humana. O eurocentrismo do modelo colonial/capitalista de poder não se deveu somente à posição dominante na nova geografia do mercado mundial, e sim, também e, sobretudo, a essa classificação social básica racial da população mundial.

Dessa forma, as sociedades latino-americanas foram construídas com a base na negação da diferença, criando um permanente estado de negação e conflito com os estados nacionais. E a inclusão pela mestiçagem foi, como em diversos contextos mundiais, uma forma de expressar a incompatibilidade das diferenças culturais e biológicas (CASTELLANOS, 1998, p.18) nessas nações, com a segregação e violência como expressões da rejeição às culturas classificadas como inferiores e bárbaras gerando o preconceito e discriminação direcionados a esses povos.

As noções dualistas de capitalismo versus pré-capitalismo, civilização versus barbárie e evolução versus atraso, dentre outras, justificaram a hegemonia europeia no nascente sistema-mundo moderno não somente no plano da dominação política e do ordenamento econômico, mas também em todas as formas de controle da subjetividade, da cultura, e em especial do conhecimento e sua produção. Maria Lugones nos aponta que:

\footnotetext{
A transformação civilizatória justificava a colonização da memória e, consequentemente, das noções de si das pessoas, da relação intersubjetiva, da sua relação com o mundo espiritual, com a terra, com o próprio tecido de sua concepção de realidade, identidade e organização social, ecológica e cosmológica. (LUGONES, 2014, p. 938).
}

As relações interétnicas ligadas a processos capitalistas asseguram as relações de exploração lógica de diferenciação combinada com desigualdades (CASTELLANOS, 1998, p.20) até os dias de hoje. Isso apesar da ênfase na herança cultural colonial ser uma das questões mais relevantes sobre a relação preconceito/discriminação. E, no caso da história das Américas, o conceito de raça se relaciona não só à variação fenotípica, mas com os enfrentamentos geográficos dos europeus em suas histórias coloniais, ou seja, expressa mais sobre a forma de pensar sobre a diferença em lugar de ser um conceito que descreva uma realidade objetiva independente do contexto social. Isto significa que essas construções não foram elaboradas somente em cima das variações fenotípicas, mas sim 
Revista Calundu - vol. 1, n.1, jan-jun 2017

sobre aspectos particulares de algumas variações fenotípicas em função dos enfrentamentos coloniais dos europeus com outros povos (WADE, 2000).

\section{Conclusão}

O artigo teve por objetivo avançar nas reflexões acerca da discriminação religiosa, contextualizando a relação histórica com a prática religiosa - a criminalização da prática do período colonial até a década de 1970, passando pelos episódios contemporâneos de intolerância, discutindo as categorias que podem ser utilizadas para caracterizar o fenômeno - intolerância religiosa, discriminação e racismo, e por fim, trazendo os aportes de autores decoloniais, especialmente no que concerne à construção da categoria raça, para compreender os reflexos da colonialidade do poder no fato aqui estudado, e auxiliar na conceituação das ações direcionadas aos praticantes de religiões de matriz africana no Brasil como racismo religioso.

Podemos apontar três elementos que no presente artigo se destacam para sustentar a hipótese de racismo religioso, hipóteses com diferentes relevâncias no sentido argumentativo, mas que valem a pena serem marcadas. O primeiro elemento é o largo histórico de marginalidade à qual essas práticas foram submetidas, tanto no sentido social como institucional - a demonização, promovida pela Igreja Católica, das entidades africanas e a criminalização do exercício religioso deixaram marcas e estigmas ainda visíveis nestas religiões, além do fato, observado na etnografia de Yvonne Maggie, de o elemento africano do culto ser o principal fator gerador do estigma.

O segundo elemento se refere à discussão conceitual. Como pudemos observar, as categorias comumente utilizadas para descrever as ações contra os religiosos contêm muitas semelhanças: a dificuldade de aceitar o outro; visão de sua cultura e suas manifestações como não corretas, não verídicas e não toleráveis; a hierarquização a partir de si, compreendendo o outro como inferior; a heterofobia (para usar a expressão de Taguieff) e a característica grupal (identidade como grupo) - a coletividade como alvo são fatores comuns tanto nas definições de discriminação, intolerância, etnocentrismo e racismo.

A diferença principal para a discussão que aqui se pretende travar está nos usos políticos das categorias sociais expostas. Exemplificando com a categoria da intolerância - observou-se no texto que a palavra tolerância carrega um forte sentido de 
condescendência e a condescendência a outrem só pode ser promovida pelo elemento de mais poder na sociedade, ou seja, o elemento hegemônico. O elemento que tem mais poder político consegue impor na sociedade "a verdade". Aqui se pode ilustrar com um exemplo real: há três anos, um juiz federal apresentou em seu veredicto que as práticas de Umbanda e Candomblé "não contêm os traços necessários de uma religião" (FOLHA DE SÃO PAULO, 2014, on-line) - sendo assim, é como se o juiz atestasse que as religiões afro-brasileiras não seriam "de verdade". A tolerância, neste sentido, é uma concessão e por esse motivo os militantes da causa atualmente têm dificuldade com o termo "intolerância religiosa", o pedido por "respeito" na fala denota um pedido por igualdade de direitos, concessões não são mais desejadas pelo claro desequilíbrio de poder apresentado.

O que sustenta a hipótese de racismo religioso, nos casos de manifestações contra religiões de matriz africana, é exatamente a afirmação da africanidade que a prática religiosa carrega - o contexto no qual os africanos foram trazidos ao país, e as representações do negro (fenótipo, cultura e cosmovisões) são o fator gerador - a característica grupal - da discriminação.

Como vimos na discussão das categorias, os fatores culturais alimentam preconceitos e criam estigmas que são reproduzidos. Nesse sentido, o terceiro elemento de sustentação da hipótese de racismo religioso tem base na criação colonial da categoria raça no continente americano como estratégia de dominação de povos escravizados. $\mathrm{O}$ eurocentrismo, ao criar uma dualidade de mundo, civilização (europeu) versus barbárie (povos colonizados), promoveu heranças no imaginário social que marcaram até hoje a religiosidade de origem afro com a estampa da "raça" inferior e bárbara.

À guisa de conclusão, pode-se defender o uso do termo "racismo religioso" como mais adequado para caracterizar as ações de discriminação/intolerância contra as religiões afro-brasileiras, uma vez que, conforme explicitado no artigo, a africanidade das práticas vinculada ao contexto histórico colonial racista são as principais motivações das ações praticadas. 


\section{Referências bibliográficas}

BASTIDE, Roger. As Religiões Africanas no Brasil: contribuição a uma sociologia das interpenetrações de civilizações. São Paulo: Pioneira, 1985 [1960].

BOTELHO, Denise, NASCIMENTO, Wanderson Flor do. "Educação e religiosidades afro-brasileiras: a experiência dos candomblés". Participação, Brasília, n. 17, jan. 2012.

CASANOVA, Pablo G. "Colonialismo interno (uma redefinição)". In BORON, Atílio A.; AMADEO, Javier; GONZALEZ, Sabrina. A teoria marxista hoje. Problemas $e$ perspectivas. Buenos Aires: CLACSO, 2002.

CASTELLANOS GUERRERO, Alicia. "Nación y Racismos". In CASTELLANOS GUERRERO, Alicia; SANDOVAL PALACIOS, Juan Manuel (coords.). Nación, Racismo e identidad. México, DF: Editora Nuestro Tiempo, 1998.

ANCIRA, García Andrea (CONAPRED). Ficha Temática Relacionada Con La Situación De Las Personas Migrantes Y Refugiados En México. México, CONAPRED (CONSEJO NACIONAL PARA PREVENIR LA DISCRIMINACIÓN), 2007.

DIAS, Julio César Tavares. As religiões afro-brasileiras no discurso da igreja universal do reino de deus: a reinvenção do demônio. 2012. 131fl. Dissertação. Mestrado em Ciências da Religião, Universidade Católica de Pernambuco, Pernambuco, 2012.

DUSSEL, Enrique. "Deconstrucción del concepto de tolerancia: de la intolerancia a la solidaridad". Comunicación presentada al XV Congreso Interamericano de Filosofía y II Congreso Iberoamericano de Filosofía. Lima, 2004.

1492: O encobrimento do outro. Petrópolis : Vozes, 1993.

"Europa, modernidad y eurocentrismo". In LANDER, Edgardo (org.). A colonialidade do saber: Eurocentrismo e Ciências Sociais. Buenos Aires: Consejo Latinoamericano de Ciencias Sociales, 2000.

FASSIN, Didier. "L'intervention française de la discrimination". In Revue française de science politique, ano 52, $\mathrm{n}^{\circ} 4,2002$. pp. 403-423.

FASSIN, Eric ; HALPERIN, Jean-Louis. "Une bréve histoire des discriminations". In FASSIN, E.; HALPERIN, J. (orgs). Discriminations: pratiques, savoirs, politiques. Paris: La Documentation Française, 2008. 
FERNANDES, Nathalia Vince Esgalha. A luta institucional antidiscriminatória: um estudo de caso do CONAPRED e da atenção à discriminação contra imigrantes centroamericanos no México. 2016. 138 f., il. Dissertação. Mestrado em Ciências Sociais, Universidade de Brasília, Brasília, 2016.

FERREIRA, J. Flávio. "Fazendo gênero no candomblé: entre o feminismo internacional e a retórica salvacionista. Por um enunciado epistemológico desde os terreiros". In Novos Rumos Sociológicos v. 4, n. 5, Programa de Pós-Graduação da Universidade Federal de Pelotas, pp. 158-181, 2016 [1985].

FLORES, Herrera. "La verdad de una Teoría Crítica de los Derechos Humanos". In MOURA, Marcelo Oliveira de. Irrompendo no Real. Escritos de Teoria Crítica dos Direitos Humanos. Pelotas: Educat, 2005.

GUIMARÃES, Antonio Sérgio Alfredo. Preconceito e Discriminação. São Paulo: editora 34, 2004 [1998], pp. 17-32.

LEE, Orville. "Race after the cultural turn". In JACOBS, M.; HANRAHAN, N. W. (Orgs). The Blackwell Companion to the Sociology of Culture. Malden: Blackwell Publishing, 2005.

LUGONES, Maria. "Rumo a um feminismo descolonial". In Estudos Feministas, Florianópolis, v. 22, n. 3, p. 935-952, jan. 2015.

MAGGIE, Yvonne. Medo do Feitiço: relações entre magia e poder no Brasil. Rio de Janeiro: Arquivo Nacional, 1992.

MALGESINI, Graciela; GIMÉNEZ, Carlos. Guía De Conceptos Sobre Migraciones, Racismo e Interculturalidad. Madrid: Catarata, 2000.

QUIJANO, Aníbal. "Colonialidad del poder, eurocentrismo y América Latina". In Revista Venezolana de Economia y Ciencias Sociales. Enero/abril, Año/Vol.10, Número 001. Caracas, Venezuela: Universidad Central de Venezuela, 2004.

SECRETARIA ESPECIAL DE DIREITOS HUMANOS (SDH). Relatório sobre Intolerância e Violência Religiosa no Brasil (2011 - 2015): resultados preliminares. Ministério das Mulheres, da Igualdade Racial, da Juventude e dos Direitos Humanos; organização Alexandre Brasil Fonseca, Clara Jane Adad. - Brasília: Secretaria Especial de Direitos Humanos, SDH/PR, 2016.

SANZ, Wagner de Campos. "Discriminação, Preconceitos e Intolerância". In MORAES, C. C. P.; LISBOA, A. S.; OLIVEIRA, L. F. (Orgs). Educação para as Relações Etnicorraciais. Brasil. Ministério da Educação. Coordenação de Aperfeiçoamento de 
Pessoal de Nível Superior. Universidade Federal de Goiás. 2 ed. - Goiânia: FUNAPE: UFG/Ciar, 2012.

SEGATO, Rita Laura. "Alteridades históricas/Identidades políticas: una crítica a las certezas del pluralismo global”. In Série Antropologia 234. Brasília: Departamento de Antropologia da Universidade de Brasília, 1998.

. La nación y sus otros: raza, etnicidad y diversidad religiosa en tiempos de políticas de la Identidad. Buenos Aires: Prometeo Libros, 2007.

SILVA JR, Hédio. "Intolerância religiosa e direitos humanos". In SANTOS, Ivanir dos \& ESTEVES FILHO, A. (Orgs). Intolerância Religiosa X Democracia. Rio de Janeiro: CEAP, 2009.

SILVEIRA, Renato da. O Candomblé da Barroquinha. Processo de constituição do primeiro terreiro de keto. Salvador: Maianga, 2006.

TAGUIEFF, Pierre-André. "El Racismo". In Cahier du CEVIPOF, n²0. Paris: 1998.

VALLE FILHO, Nelson. "Prefácio". In GUIMARÃES, Antonio S. A. Preconceito e Discriminação. Queixas e ofensas de tratamento desigual dos negros no Brasil. Salvador: Ed. Novos Toques, 1998.

WADE, Peter. Raza y etnicidad en Latinoamerica. Quito: Ediciones Abya Yala, 2000.

WIEVIORKA, M. O Racismo, uma introdução. São Paulo: Perspectiva, 2007.

\section{Reportagens}

AGENCIA BRASIL (EBC), 2015. Disponível em: http://agenciabrasil.ebc.com.br/direitos-humanos/noticia/2015-07/negros-e-religioesafricanas-sao-os-que-mais-sofrem-discriminacao. Acesso em 10/05/2017.

BRASIL DE FATO, 2017. Disponível em: https://www.brasildefato.com.br/2017/01/21/artigo-or-e-sobre-racismo-religioso-queprecisamos-falar/. Acesso em 10/05/2017.

FOLHA DE SÃO PAULO, 2014. Disponível em: http://www1.folha.uol.com.br/poder/2014/05/1455758-umbanda-e-candomble-nao-saoreligioes-diz-juiz-federal.shtml. Acesso em 10/05/2017. 
Revista Calundu - vol. 1, n.1, jan-jun 2017

FOLHAPE,

2016.

Disponível

em:

http://www.folhape.com.br/noticias/noticias/cotidiano/2016/11/16/NWS,6481,70,449,N OTICIAS,2190-DIA-INTERNACIONAL-TOLERANCIA-LEVANTA-DISCUSSAOSOBRE-RESPEITO-DIFERENCAS.aspx. Acesso em 10/05/2017.

UOL Notícias, 2015. Disponível em: https://noticias.uol.com.br/ultimasnoticias/agencia-estado/2015/06/16/menina-e-apedrejada-na-saida-de-culto-decandomble-no-rio.htm. Acesso em 10/05/2017. 